Session 3251

Session 3251

\title{
Engineering Babies in Mathematical Bathwater: the Hydrogeology 'ILAP'
}

\author{
John H. Grubbs, Michael B. Kelley, and Joseph D. Myers \\ United States Military Academy
}

\section{Introduction: Guilty as Charged}

The accusation is simple: We have allowed too many students to fall by the wayside before reaching their first engineering course because of mathematics. In effect, we have been throwing out engineering babies in mathematical bathwater. However, as much as we in the engineering community desire to throw stones, we need to realize that the problem was born on a two-way street. Until now, collectively we have done very little to improve the situation. This paper describes continuing efforts ${ }^{1}$ to effect a cultural change in the interaction between the mathematics and engineering communities. Through the use of 'ILAPs' - Interdisciplinary Lively Application Projects - this initiative focuses on insuring the mathematics education serves as a 'pump' for student success in engineering, as opposed to being a filter. An environmental engineering example of the 'ILAP' is presented using concepts in hydrogeology. In solving problems related to groundwater flow in their junior year elective mathematics course, cadets from the United States Military Academy who are majoring in environmental engineering learn firsthand of the linkage between mathematical concepts and engineering problem solving. The linkage established in the mathematics course is strengthened in design scenarios presented during their environmental engineering course in hydrogeology. Improved student success and increased communication between mathematics and engineering faculty are the products of the 'ILAP'. As part of a National Science Foundation initiative known as Project Intermath, a consortium of schools has been formed to export both the 'ILAP' and the associated cultural change in mathematics education on a national scale.

\section{A History of Interdisciplinary Lively Application Projects}

An initiative of the Department of Mathematical Sciences at the United States Military Academy in the late 1980's attacked the age-old problem (an erroneous perception according to some, a major real problem to others) labeling mathematics education as a 'filter' opposing rather than a 'pump' assisting student success. The charge has been that many students leave the field of engineering before taking a first engineering course largely because of a negative experience in mathematics. The department attacked the 
problem in a manner that resulted in a win-win situation for the math-science-engineering (MSE) community at West Point. Known as 'ILAPs' - Interdisciplinary Lively Applications Projects - the initiative has resulted in improved communication among the MSE departments; introduced cadets to engineering problem solving beginning during their first semester at the Academy; and, resulted in a measurable increase in cadet enthusiasm for mathematics, basic and engineering sciences, and engineering. Since its inception, the ILAP effort has been strongly endorsed by the Department of Geography and Environmental Engineering. From its introduction into the mathematics curriculum, the ILAP has grown to where it is now the central component of a National Science Foundation initiative, Project Intermath.

\section{The ILAP Concept}

The concept of the Interdisciplinary Lively Applications Project is to introduce a real world engineering problem early into a cadet's mathematics education. As an example, pollution of the Great Lakes has been ideal for first year students. Most have heard the horror stories of Lake Erie, many have a genuine interest in 'saving the environment', and almost all of the cadets like the idea that mathematics does serve a usual purpose. Other problems cover the spectrum of the sciences and engineering from modeling bungee jumping, to climbing Pike's Peak, to containment of forest fires. Depending upon the sophistication of the problem, the solution could involve a single cadet or a small group of cadets working as a formal team. The general sequence of events is as follows:

* Scope out the problem

* Model the problem situation

* Solve the problem

* Analyze long term behavior

* Confirm results (spreadsheet)

* Write a technical report

* Make an oral presentation

In cases involving group effort, mastery of the subject material is measured by a quiz for individual grade following the termination of each project.

In many instances, a professor from the supported discipline involved (e.g., environmental engineering) will provide a solution to the entire class. In some cases, the professor will have the opportunity to discuss the discipline (bungee jumping and mechanical engineering, hydrogeology and environmental engineering, etc.) from which the problem was developed. Discussions in such a forum have led to increased enrollments in engineering programs here at the Military Academy.

\section{The Hydrogeology ILAP}


In the environmental engineering program, cadets must take a directed, environmental engineering focused mathematics elective, MA 366, Vector Calculus and Introduction to Partial Differential Equations, in the spring of their junior year. Our predecessors have developed the 'Hydrogeology ILAP' to link the math course to the engineering applications course taught the following semester. Through interaction between faculty members of the Department of Mathematical Sciences and the Department of Geography and Environmental Engineering, this problem is first introduced in MA366 and, further downstream (excuse the pun), it is revisited in EV394, Hydrogeology. The fruit of the effort is seen in inculcating in each cadet the interconnectedness between mathematics and engineering. It is marvelous for cadets to first realize that the concepts related to groundwater flow can be modeled in mathematics in a way that will lead to real solutions for engineering problems. Later on, in hydrogeology, the cadets are relieved to find that the mathematical concepts emphasized in groundwater flow are not all that difficult. For clarification, let's take a look at the Hydrogeology ILAP.

\section{Groundwater Flow - the Mathematical and Engineering Problem}

This ILAP was co-developed previously and has been refined / currently executed by the second and third authors -- an engineer and a mathematician. On the third day of class (after prerequisite skill preliminaries), we walk into the math class of fledgling engineers in training and set the stage:

It's late fall at an Alaskan airport, and there is a large-area ground oil spill with continued leakage (that maintains the surface at a constant level of contaminant concentration). The contamination is being advected by surface runoff and is also diffusing downward toward bedrock level, and we (the class) need to predict the evolution of both processes over time. That is, where will the runoff contamination spread to; what is the effect of vorticity on measurement equipment in bore holes that we dig; when will the contamination reach permafrost level; and finally, how deep will the contaminants be when the spring melting comes? We tell them that we also need to predict the differences that would be caused by rainwater advection (downward) if we have a warm wet winter rather than a cold snowy one.

Given their mathematics courses to date (discrete dynamical systems, calculus I and II, and probability and statistics), it is obvious that the cadets cannot answer these questions yet. However, we indicate that they will need the vector calculus, PDE, and numerical analysis tools in the three upcoming blocks that comprise the course in order to keep from throwing out the baby in the mathematical bathwater, that is, to tackle this problem. We also affirm -- directly to them in the math classroom -- that the math they are currently learning will be necessary for their success in the following hydrogeology course and in the remainder of their program. 
We divide the class into work teams and hand out the project -- a multi-requirement, three part document that outlines the problems which we had summarized for them. During subsequent lessons of the vector calculus block, we develop the basic differential vector operators and the integral vector theorems. As we develop these ideas and tools in class, we allude to how they relate to the project requirements. Students are encouraged to work on the project throughout the block in parallel with our classroom development of the mathematics.

At the end of the vector calculus block (11 lessons later), we formally return to the project. Teams turn in their projects, and each briefs their solution to one portion of the project. During the last half of the class, we then show the students how these project ideas that they have studied can be (and will be in later courses) extended to more general advection problems in atmospheric, reservoir, and water table modeling (e.g., through Darcy's law). We repeat this process in the next two blocks of the course as well. In the PDE block, students use separation of variables and Mathcad ${ }^{\mathrm{TM}}$ to investigate the pure groundwater diffusion scenario (with extensions to flow nets and creeping potential flow in porous soil). In the final block on numerical methods, students use Excel ${ }^{\mathrm{TM}}$ and finite differences to investigate the combined diffusion-advection scenario, with extensions to more realistic, messier groundwater flow problems (via the Navier-Stokes equations). We also introduce the students to the numerical code of the Saturated and Unsaturated TRAnsport [SUTRA] Model, which all of the students will be using in their followingsemester hydrogeology course to investigate these messier problems.

The mathematics course just described sets up the engineering applications course EV394, Hydrogeology. In the hydrogeology course we introduce cadets to porosity, permeability, Darcy's Law, potentiametric surfaces, Laplace and Theis Equations, diffusion, dispersion and advection/dispersion. We supplement the class materials with the SUTRA Model and weave the use of this model into the term project - an evaluation of organic contaminant transport in the subsurface strata at Rocky Mountain Arsenal, CO.

We feel that ILAP's such as this give students an immediate and tangible reason for mastering the tools of mathematics (both analytic and software). ILAPs excite them about the engineering opportunities that open to them when they are successful in the math classroom. Finally, ILAPs give us a chance to plant seeds early in the program that can be fruitfully revisited in later courses. The future of this math/engineering marriage for these particular courses may include actual team teaching of this material.

\section{To the Future: Project Intermath}

As a result of the success of the introduction of ILAPs into the mathematics and engineering curriculums at the United States Military Academy, a funding grant was provided by the National Science Foundation to use 'Project Intermath' as a conduit to effect a cultural change in the way that mathematics is both taught and the manner in which the mathematics community relates to other discipline. While this discussion has 
focused on engineering application of the ILAP, the concept is as applicable to any discipline which has a requirement for a mathematical foundation.

Project Intermath now consists of a consortium of institutions ranging from community colleges to larger research institutions. Our ranks include:

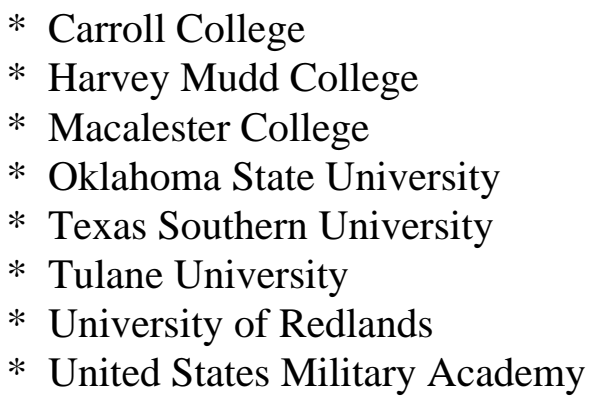

A dual focused process is underway which focuses on the development of ILAPs and the implementation of a dissemination plan to export Project Intermath on a national level. The Consortium for Mathematics and Its Applications (COMAP) has joined with us to insure that the publication of ILAPs is professional in all respects. ${ }^{2}$ We are now in our first year of funding and have begun the implementation of the dissemination effort. A snapshot of the plan to export Project Intermath is as follows:

\section{Year 1:}

ILAP development and revision

National mailings

Journal publications

National conference presentations

Establishment of an Internet network

Development of a feedback loop

Initiation of workshops at West Point

\section{Year 2:}

All of the above

Workshops at regional/national conferences

Presentations at dean's conferences

Workshops at consortium institutions

\section{Year 3:}

All of the above

Establishment of ILAP plenary sessions

Training teams to 'new' institutions

Teleconferencing of workshops

\section{Years 4 and 5:}

All of the above 


\section{New institutions implement workshops}

At this point, the consortium is alive and well. Workshops held at West Point and Harvey Mudd College have been vibrant and productive. With the center of activities located within the Department of Mathematical Sciences at the United States Military Academy, we are committed to the goal of changing the culture of our mathematics, science and engineering teaching communities. In engineering, our success will be measured in the numbers of new students who have been 'turned on' as opposed to 'turned off' as they passed through the mathematics spigot.

\section{References:}

1. Jardine, Richard J., "Interdisciplinary Mathematics for Environmental Engineers," Paper 2265, American Society for Engineering Education (ASEE) 1996 Annual Conference, Washington, DC, June 23-26, 1996.

2. An Introduction to the Interdisciplinary Lively Applications Project, The Consortium for Mathematics and Its Applications (COMAP), Lexington, Massachusetts, 1995.

JOHN H. GRUBBS. Colonel John H. "Jack" Grubbs, a 1964 graduate of the United States Military Academy, is Professor and Head, Department of Geography and Environmental Engineering, USMA. He holds a Ph.D. in Civil Engineering from Rensselaer Polytechnic Inst. and is a Professional Engineer. His service includes two tours in Vietnam as a combat engineer, and service in Okinawa, Korea, and the US.

MICHAEL B. KELLEY. Lieutenant Colonel Michael B. "Mike" Kelley, a 1974 graduate of Norwich University, is an Assistant Professor in the Department of Geography and Environmental Engineering, USMA. He holds a Ph.D. in Environmental Engineering from Rensselaer Polytechnic Institute and is a Professional Engineer. Mike's service includes tours in Texas, Maryland, Germany and West Point.

JOSEPH D. MYERS. Lieutenant Colonel Joseph D. "Joe" Myers, a 1978 graduate of the United States Military Academy, is an Associate Professor in the Department of Mathematical Sciences, USMA. He holds a Ph.D. in Applied Mathematics from Harvard and is a Professional Engineer. Joe's service includes tours in Korea, Maryland, Texas, Alabama, North Carolina, Washington DC, and West Point. 